\title{
Blended Instructional Design Based on Microlecture-Take English Phonology Course as an Example
}

\author{
Xingchi Zhao \\ Harbin Vocational College of Science and Technology, Harbin, China, 150300 \\ zxc321222@163.com
}

Keyword: Internet + education, Microlecture, English Phonology, Blended instructional design

\begin{abstract}
Under the background of "Internet +" education, online learning methods such as microlecture, MOOC, and spoc have emerged, which greatly enriched educational resources and teaching measures. This article takes the English Phonology course as an example to make a instructional design based on microlecture. In teaching procedure, it uses three kinds of informational technology, which are the 3D effect of mind map, microlecture, and GIF animation created by Adobe photoshop software, and it uses Tsinghua Rain Classroom as an important supplementary means to achieve pre-class sign in, in-class practice, after-school feedback and etc. Practice has proved that this blended instructional design makes the teaching content more vivid and deepens the students' understanding of the learning content. It has achieved good results.
\end{abstract}

\section{Introduction}

With the advent of the "Internet+" era, the concept of open sharing has profoundly influenced and changed people's lives. The way to obtain information anytime and anywhere through mobile devices has been accepted by more and more people. The corresponding "Internet +" education has gradually entered the people's field of vision. The construction of the national online open resource library has begun to take shape.The Ministry of Education issued the "Opinions of the Ministry of Education on Strengthening the Application and Management of Online Open Courses in Colleges and Universities " in April 2015. Courses such as microlecture, MOOC, and Spoc have been effectively promoted. The term microlecture is not used here to refer to microcontent for microlearning, but to actual instructional content that is formatted for online and mobile learning using a constructivist approach[1]. MOOC is massive open online course. Spoc is small private online course.

Teachers should fully recognize the opportunities and challenges brought by the "Internet +" era, and constantly improve their thinking quality, professionalism and internet application capacity. They should realize the transformation from traditional teaching to information-based teaching, from single-mode teaching to blended teaching, from teacher-directed to student-oriented learning.

\section{Tools}

There are many platforms to support microlecture learning and production, such as the internationally famous TED talks and KHAN academy. In China, there are http://www.mooc.cn, http://www.icourses.cn for higher education and http://www.icve.com.cn for vocational education. http://www.yoya.com for making cartoon or animations. Teachers also could use softwares to design and produce microlecture. The teacher adopts the following softwares to make the blended instructional design, see Table 1. 
Table 1 Tools applied in blended instructional design

\begin{tabular}{|c|c|}
\hline Objects & Tool names \\
\hline presenation & PowerPoint, Focusky \\
\hline mind map & IMindMap \\
\hline recording & Camtasia Studio \\
\hline image processing & Photoshop \\
\hline management & Tsinghua Rain Classroom \\
\hline
\end{tabular}

\section{Blended Instructional Design}

The so-called blended instructional design is based on the traditional classroom teaching content, combined with multimedia, microlecture and other elements in the teaching process. It can enrich teaching contents and improve teaching quality, so that students can learn and absorb most of their knowledge in limited time and space environment. A typical blended teaching form is shown in Fig. 1 below.

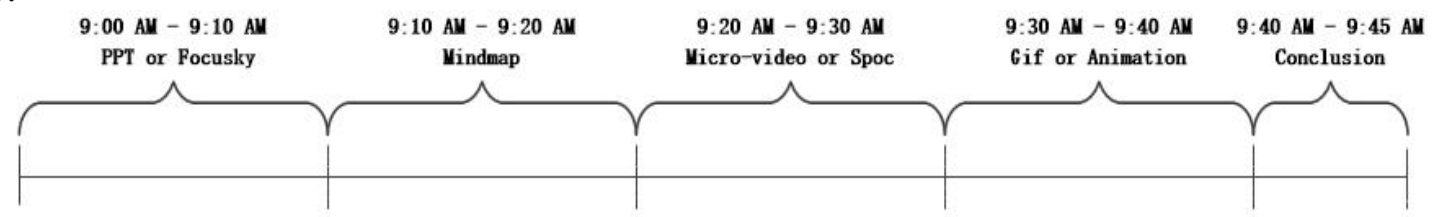

09:00

Figure 1. A typical time allocation of blended teaching content

This is a 45-minute course with the following teaching process:

1) PPT or Focusky gives an outline of the main content of this section, emphasizing the key points and difficulties.

2) Mind map.

3) Microlecture.

4) Animation.

5) Summary.

The above content uses the softwares in table 1.

It should be noted that: (1) The above teaching steps may be increased or decreased according to the needs in actual teaching, and the order may be adjusted. (2) Because of the use of multimedia, the switching time of steps can be neglected.

The following is a case of the teaching design of English Phonology course with blended teaching mode.

\section{Example-English Phonology Course}

The teaching content is the plosive consonants in Chapter V of the "English Phonology" course, and the blended instructional design based on the microlecture is carried out.

\subsection{Introdution(PPT or Focusky).}

The teacher makes the brief introduction of the course by PPT or Focusky. Make sure the students understand the teaching aim and learning objectives. Outline the knowledge points and difficulties of this class and make other necessary quirements.

\subsection{Classification of Consonants(IMindMap).}

As a common sense, the consonants can be divided into two categories which are voiceless consonants and voiced consonants, see Table 2. 
Table 2 Voiceless consonants vs voiced consonants

\begin{tabular}{|c|c|}
\hline voiceless consonants & $/ \mathrm{ptkfs} \int \theta \mathrm{ht} \int \mathrm{ts} \mathrm{tr} /$ \\
\hline voiced consonants & / b d g v z 3 ð rdz m n g $1 \mathrm{wj} \mathrm{dz} \mathrm{dr/}$ \\
\hline
\end{tabular}

According to the manner of articulation, consonants can be further divided into six groups, see Fig. 2.

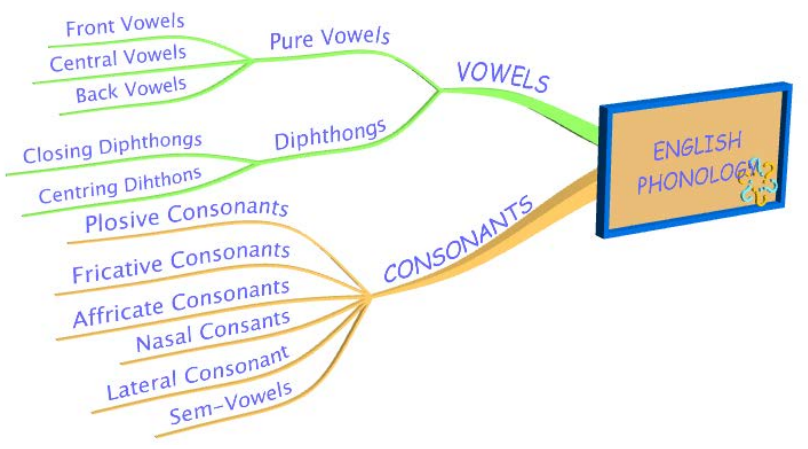

Figure 2 IMindMap of English Phonology

We can see clearly that Table 2 is a static graphic, which is composed of four columns based on straight lines. Table 2 shows the two-dimensional effect of the simple relationship between elements. Fig. 2 adopts the IMindMap software to illustrate complicated relationships of English Phonology. Both teachers and students prefer Fig. 2 to Table 2, because IMindMap is flexible, creative, convenient and easy to learn. We can make good use of powerful tools to design the class in various ways, for instance, taking advantage of modules, creating 3D presentation, outputting the results in different forms and so on.

\subsection{Plosive Consonants(Camtasia Studio).}

In this part, the techer teaches the plosive consonants by a microlecture. The microvideo recording can be done in two general ways: one is adopting a camera or an intelligent phone to take a real shot, and the other is adopting the software such as Camtasia Studio to complete the recording, synthesis, editing, subtitles and etc.

The teacher applies a live shooting method. There are two cameras in a room about 30 square meters, one is at the front and the other is at the back. We must keep the room quiet and keep a distance from the disturb origins. The teacher installs the screen recording software in the computer. So we can see the teacher activies, teaching contents and students activities simutanously, see Fig. 3.

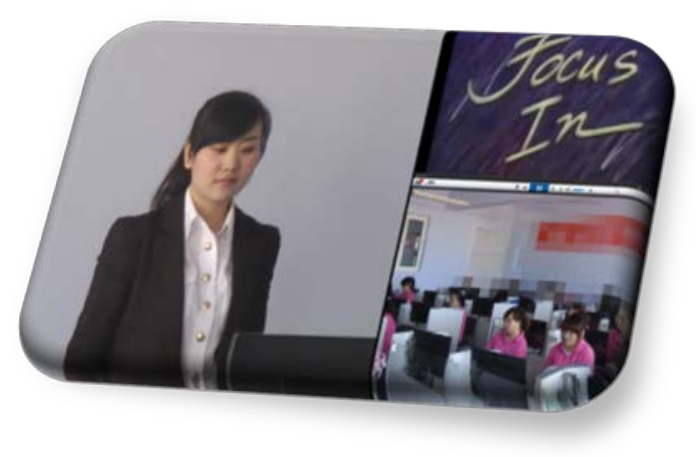

Figure 3. Microlecture

In addition to shoot a video, the teacher also could select the teaching materials from the internet. It has three advantages by using video materials: It could provide a vivid illustration of the whole process of pronunciation. It could provide a sharp contrast between different sounds. It could strengthen the pictorial effect as well as lower the costs of production by inserting the video into presentation. 


\subsection{Pronunciation Rules(GIF animation created by Adobe Photoshop).}

There two rules.

Rule 1:When a plosive meets another plosive, it will lose plosion, which is called loss of plosion.

Rule 2: When a plosive meets other consonants (fricative, affricative, nasal or laeral consonants), the first plosive forms obstruction and quickly turns to the next sound. This process is called incomplete plosion.

The teacher applies the Adobe Photoshop software to produce GIf animation, see Fig. 4.

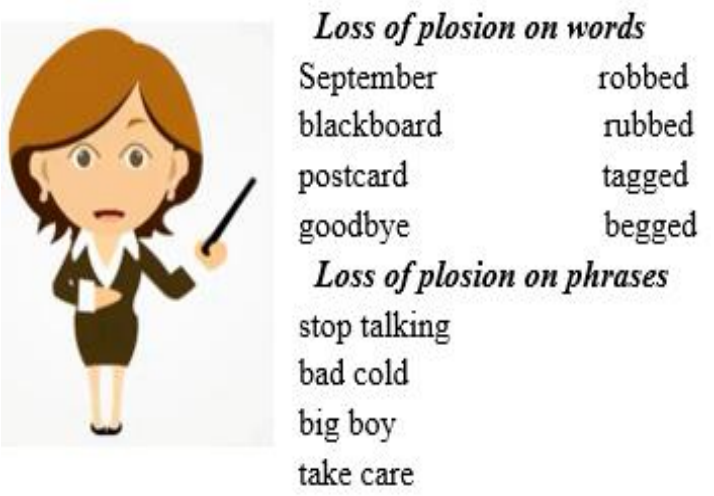

Figure 4. GIF animation

\subsection{Practice(Tsinghua Rain Classroom).}

Teacher also uses Tsinghua Rain Classroom as an important supplementary means to assist teaching and management. In the Rain Classroom, students sign in with their mobile phones so as to save time costs. The learning contents and exercises are pushed to the students through the Rain Classroom. The teacher can grasp the actual learning effects by students' answers and take effective measures to improve teaching quality.

\section{Summary}

This paper takes the "English Phonology" course as an example to complete blended instructional design based on microlecture. The softwares used are PPT, Focusky, Imindmap, Camtasia, Adobe photoshop. At the same time, Tsinghua Rain classroom is used as an important supplementary means. Practice has proved that this blended instructional design makes vivid description of the knowledge, absorbs students attention in longer time and hence deepens the students' understanding of the learning content. It has achieved good results.

\section{References}

[1] Shieh, David. (2009). These lectures are gone in 60 seconds. Chronicle of Higher Education,55(26), A1,A13.

[2] Liu Wanhui. Microlecture development \& Production Techiques. Higher Education Press(2015)

[3] Cao M. An Overview of Micro-Lecture in College English Teaching in Mainland China. International Journal of Language and Linguistics, 2017, 5(2): 34.

[4] Wu Y. Research Summary of College English Micro-lecture in China. Journal of Language Teaching and Research, 2018, 9(4): p777-783.

[5] Zhang, W. \& Zhang, E. (2018). On China’s English Teaching Reform: From Micro-lesson and MOOCs to Flipped Class. International Journal of Emerging Technologies in Learning (iJET), 13(1), 220-229. 